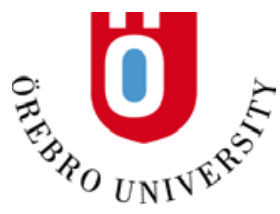

SCHOOL OF BUSINESS

WORKING PAPER

$3 / 2012$

(Revised February 2016)

Temporal Aspects of the Social Cost of Greenhouse Gases

Disa Thureson

Economics

ISSN 1403-0586

https://www.oru.se/institutioner/handelshogskolan/forskning/working-papers/

Örebro University School of Business

70182 Örebro

SWEDEN 


\title{
The Temporal Aspects of the Social Cost of Greenhouse Gases
}

\author{
Disa Thureson \\ The Swedish National Road and Transport Research Institute (VTI), \\ Division of Transport Economics, \\ and Örebro University School of Business, Sweden
}

February 2016

\begin{abstract}
The purpose of this study is to investigate the temporal aspects of the social cost of greenhouse gases (GHGs). I am particularly interested in the interaction between time of emissions, discounting, and type of GHG (where different GHGs have different atmospheric lifetimes). I show graphically how the social costs of GHGs depend on different parameter values and how the global damage potential for methane and sulfur hexafluoride evolves over time. I find that that the calculation period ultimately should be modeled to be consistent with the discount rate and that the "global-warming potential" concept is unsuitable for calculating of the social cost of GHGs other than carbon dioxide.
\end{abstract}

Keywords: Cost-benefit analysis; Discount rates; Emissions pricing; Global warming potential

JEL codes: Q54 


\section{INTRODUCTION}

The social cost of carbon dioxide $\left(\mathrm{SCCO}_{2}\right)^{1}$ is the cost of the damage caused by emitting one additional unit of carbon dioxide $\left(\mathrm{CO}_{2}\right)$ and is typically expressed in U.S. dollars per metric ton of $\mathrm{CO}_{2}$. It is known that the temporal aspects are of great importance for such calculations, but most of the focus until now has been on discounting. In this study, I examine the temporal aspects in more depth and focus on the interactions between different temporal aspects using the PAGE2002 model2.

$\mathrm{SCCO}_{2}$ estimates are calculated by using Integrated Assessment Models (IAMs) that combine simplified versions of climate models with socioeconomic models on a global scale. A number of studies have shown that $\mathrm{SCCO}_{2}$ is highly sensitive to discounting. There have also been studies exploring how $\mathrm{SCCO}_{2}$ develops over time (notably Marten and Newbold, 2012), and they have generally found an increasing trend. A few other studies have looked at the relationship between the social cost of greenhouse gases (GHGs) with different atmospheric lifetimes. However, explicit comparisons of the growth rate of different GHGs with respect to discount rate have to my knowledge not been performed, nor has the impact of calculation period been explored.

The purpose of this study is to investigate the temporal aspects of the social cost of GHGs. I am particularly interested in the interaction between time of emission, discounting, and type of GHG (where different GHGs differ in atmospheric lifetimes). Two particular questions that I aim to answer are how the calculation period should be set and whether global warming potentials (GWPs) can be used to calculate the social cost of GHGs other than $\mathrm{CO}_{2}$.

Two aspects of $\mathrm{SCCO}_{2}$ are explored in this paper, the sensitivity to discounting parameters; and the influence of the calculation period. First, a partial sensitivity analysis of $\mathrm{SCCO}_{2}$ with respect to the pure rate of time preference (PRTP) and the elasticity of marginal utility of consumption (EMUC) is performed. Second, the influence of the calculation period for $\mathrm{SCCO}_{2}$ is examined. In addition, two aspects of different GHGs are analyzed, in each case with two different discount schemes: social costs and global damage potentials, and growth rate over time. Analyses are performed for $\mathrm{CO}_{2}$, methane $\left(\mathrm{CH}_{4}\right)$, and sulfur hexafluoride $\left(\mathrm{SF}_{6}\right)$. The main conclusions are that the calculation period should ultimately be modeled to be consistent with the discount rate and that this work confirms the notion that GWPs cannot be used to reliably calculate the social costs of GHGs other than $\mathrm{CO}_{2}$.

\footnotetext{
${ }^{1}$ Often the term social cost of carbon, SCC, is used in the literature, which refers to the social cost of emitting one mass unit of pure carbon into the atmosphere in the form of carbon dioxide. One mass unit of carbon results in 3.66 mass units of $\mathrm{CO}_{2}$

${ }^{2}$ For a specification of the model, see Hope (2006).
} 


\section{PREVIOUS LITERATURE}

This area of research has been characterized by deep differences and controversies between the scientists working in the field. The Stern Review (Stern 2006) triggered much debate by deriving much higher $\mathrm{SCCO}_{2}$ estimates than the mainstream literature at the time, largely due to a different view on the ethics involved in intergenerational trade-offs in combination with a more sophisticated treatment of uncertainty (Dietz et al. 2007).

The standard way to address inter-temporal tradeoffs in cost-benefit analysis (CBA) is to apply a discount rate, which means that future consumption bears relatively less weight than current consumption. Before the Stern Review, the discount rate was often set to match market rates. One reason why market rates are problematic is because there is no single market rate. The market rate is situation specific and varies with society, time, and perceived risk. In addition, in the case of global warming, the risk profile is non-conventional. Normally, an investment means that a decision on a large, non-divisional capital expenditure is made at a single point in time in order to get a stream of small returns in the future. In such a case, the largest potential loss is that the invested capital gets lost altogether, and hence a larger discount rate will account for this risk. However, in the case of global warming, the investment is made as an expenditure flow over an extended period of time, while the worst possible outcome is the destruction of mankind. Using a higher discount rate leads to a lower level of mitigation, which means that the risk of disaster increases.

The Stern Review argued, based on the previous literature on the subject, that a number of features distinguish climate effects from other externalities; it is a global problem, damages are long term and persistent, uncertainties are large, and there is a risk of large, non-marginal effects (Stern 2006, ch 2). The Stern Review used an approach that was practically similar to the Ramsey rule of discounting:

$r=\delta+\eta \cdot g$

where $r$ is the discount rate, $\delta$ is the PRTP, $\eta$ is the EMUC, and $g$ is the growth rate of per capita income.

When the Ramsey rule is used, the challenge to establish the PRTP remains. The Stern Review argued that the only rational and ethical reason for the PRTP is the annual risk that the human race would go extinct for reasons other than climate change. In line with this argument a low PRTP of $0.1 \%$ per year was used for the numerical analyses (Stern 2006, chs. 2 and 6). After the debate following the Stern Review, more attention has been paid to the theoretical side of this area, focusing mainly on discounting and the handling of extreme uncertainty (e.g., Dasgupta (2008), Gollier (2009), Weitzman (2009)). There is, however, no consensus on what a possible solution to these difficult issues would look like. 
Several studies have shown that $\mathrm{SCCO}_{2}$ is highly sensitive to the PRTP and the EMUC, notably Guo (2004), Hope (2008a), and Anthoff et al (2009). ${ }^{3}$ Furthermore, Hope (2008a) showed that when the Ramsey rule of discounting is applied $\mathrm{SCCO}_{2}$ estimates are lower as the values of the EMUC increase. The modest contribution from the present study on the sensitivity of discounting is to analyse the curvature of the sensitivities in place of point estimates.

One part of this paper is an analysis of the development of the social costs of different GHGs over time. Hope (2008b) showed that $\mathrm{SCCO}_{2}$ increases over time by about 3\% per year in an optimal scenario according to the PAGE2002 model. Marten \& Newbold (2012) used a combination of MAGICC and DICE models to show how the growth path social cost of GHGs depends on the discount rate and the GHG being studied. However, they did not include sulfur hexafluoride, which I have included in the present study. In addition, their results were presented in a different manner compared to the present study such that the growth rates of the social cost of different GHGs with different discount schemes were not explicitly compared.

Hope (2005) developed the idea that the social cost of methane should not be calculated using the GWP, which does not include socioeconomic considerations but is based solely on the physical properties of the gas(see IPCC (2001)). Instead, Hope suggested that the social cost of methane should be calculated by an IAM. ${ }^{4}$ Marten \& Newbold (2012) and Waldhoff et al. (2014) studied global damage potentials of various GHGs, which are defined as the ratio between the social cost of an arbitrary GHG and $\mathrm{SCCO}_{2}$. They used two competing IAMs, the FUND model and a combination of MAGICC and DICE, to show that the GWP is inadequate to use in place of global damage potentials. Waldhoff et al. (2014) showed that the use of GWP typically underestimates the global damage potentials, that global damage potentials are typically highly sensitive to PRTP, and that the effect of an increase of PRTP on global damage potentials goes in different directions for different GHGs. In this study, I provide an additional investigation into the global damage potential of GHGs using the PAGE2002 model.

\footnotetext{
${ }^{3}$ Of these, only Hope (2008a) used the same model as in this study, but no partial sensitivity analysis was performed in that study. The only study that presented a full partial sensitivity analysis was Anthoff et al (2009), but they used a different model from this study.

${ }^{4}$ PAGE95 was used in this study.
} 
PAGE2002 is a Monte Carlo simulation-based IAM including 86 stochastic parameters related to both climate and economic mechanisms. However, the underlying forecasts of yearly total emissions, population growth, and economic growth per region are treated as deterministic and exogenous. Most parameter values are taken from the Intergovernmental Panel on Climate Change (IPCC) Third Assessment Report (TAR) (IPCC 2001). The default time horizon for the calculations is the year 2200, and all values are in year 2000 real prices. ${ }^{5}$ Note that $\mathrm{CO}_{2}$ fertilization is not modeled explicitly in PAGE2002, which Waldhoff et al. (2014) showed is of importance when global damage potentials are calculated. For a more through specification of the PAGE2002 model, see Hope (2006).

For the purpose of this study, a range of simulations with PAGE2002 were performed to test how the $\mathrm{SCCO}_{2}$ results are influenced by different assumptions and different values for some of the most important parameters. All simulations were run with 10,000 iterations so that each simulation results in 10,000 observations from which different statistical measures can be derived.

Two different discount schemes, called Base case and Stern, were used, with different values of PRTP and EMUC. The Base case discount scheme refers to the default setting in the PAGE2002 model, and uses a triangular probability distribution with for the two parameters considered. The Stern discount scheme refers to the parameters used in the Stern Review (Stern 2006). The parameter values of the two discount schemes are presented in Table 1.

\begin{tabular}{lcc}
\hline Discount schemes & Base case & Stern \\
\hline Pure rate of time preference, $\boldsymbol{\delta}$ & $(0.1 \% ; 1 \% ; 2 \%)^{*}$ & $0.1 \%$ \\
Elasticity of marginal consumption, $\boldsymbol{\eta}$ & $(0.5 ; 1 ; 2)^{*}$ & 1 \\
\hline
\end{tabular}

Table 1: Two different discount schemes used in this study, where the discount rate is the Ramsey rule combination of these two parameters. The influence of the per capita economic growth rate was not tested, and hence $g$ is always set as in the original PAGE2002 setting (it varies between different regions and time periods). *Denotes a triangular probability density function with (min; mode; max), where min is the minimum of the values where the density is positive, mode is the value where the density is maximum, and max is the supremum of the values where the density is positive.

Previous work (eg. Anthoff et al (2009)) has shown that the discount rate has a major influence on the $\mathrm{SCCO}_{2}$. In the present study, the two parameters that given the regional rate of economic growth - determine the discount rate are the PRTP and the EMUC. Researchers disagree, however, on how these concepts should be interpreted. Advocates of a descriptive view think that these parameters should match observed behavior, while advocates of a normative approach think that besides using information on revealed preferences the parameters should be based on moral and common sense considerations (see Baum 2009). In the first approach, there is only one source of uncertainty - the estimation uncertainty of the empirical parameters - while in the second approach there is also uncertainty about the normative parts of these

\footnotetext{
${ }^{5}$ Note that PAGE2002 uses income weighting of costs and benefits between different regions. However, in Essay 2 I show that an error in PAGE2002 erases the influence of income weighting on the $\mathrm{SCCO}_{2}$.
} 
parameters. In this study, I have performed a partial sensitivity analysis of these parameters where the uncertainty can be viewed either as an empirical estimation uncertainty or as a normative policy uncertainty, or as both.

I estimated the influence of each of these two parameters in turn by setting all other parameters to their base case distributions and varying the parameter in question. The results of these estimations are shown in Figures 1. Each discrete evaluation point in the figures represents one simulation of 10,000 iterations.

While the default time horizon for the calculations in the PAGE2002 model is the year 2200, the impact of the length of the calculation period was investigated by comparing the default scenario with a scenario where the calculation period is prolonged to the year 3000 . This was done by simply extrapolating all of the results from the final calculating period in the default scenario - only changing the discount factors - by adding five new periods with identical outputs. The impact of calculation period was tested for both the Default discount scheme and Stern discount scheme. Also, a low discount scenario was studied with $\delta=0.05$ and $\eta=0.5$ (referred to as the Low discount scheme). The results are shown in Table 2.

In PAGE2002, $\mathrm{CO}_{2}, \mathrm{CH}_{4}$, and $\mathrm{SF}_{6}$ are modeled separately, and this allows for separate evaluations of social cost. ${ }^{6}$ The social costs of these three GHGs are shown in Table 3, along with their global damage potentials, for the year 2001. The growth rates of the social costs of GHGs depend on the discount rate and the gas in question. Simulations were run with two different discount schemes and with the year of emission varying from 2000 to 2080 (there are seven different analysis years in this interval). In total, 14 simulations were run for each GHG. The reported outputs are the net present values with emission year as the calculation year (in year 2000 real prices). The growth rates of the social costs of these three gases are compared in Figure 3.

\footnotetext{
${ }^{6}$ Note that $\mathrm{CO}_{2}$ fertilization is not modeled explicitly in PAGE2002, which means that this effect cannot be distinguished between different gases.
} 
Figure 1 shows the results from the partial sensitivity analysis of the discount parameters over a wide range together with the min, mode, and max in the default triangular distribution setting.

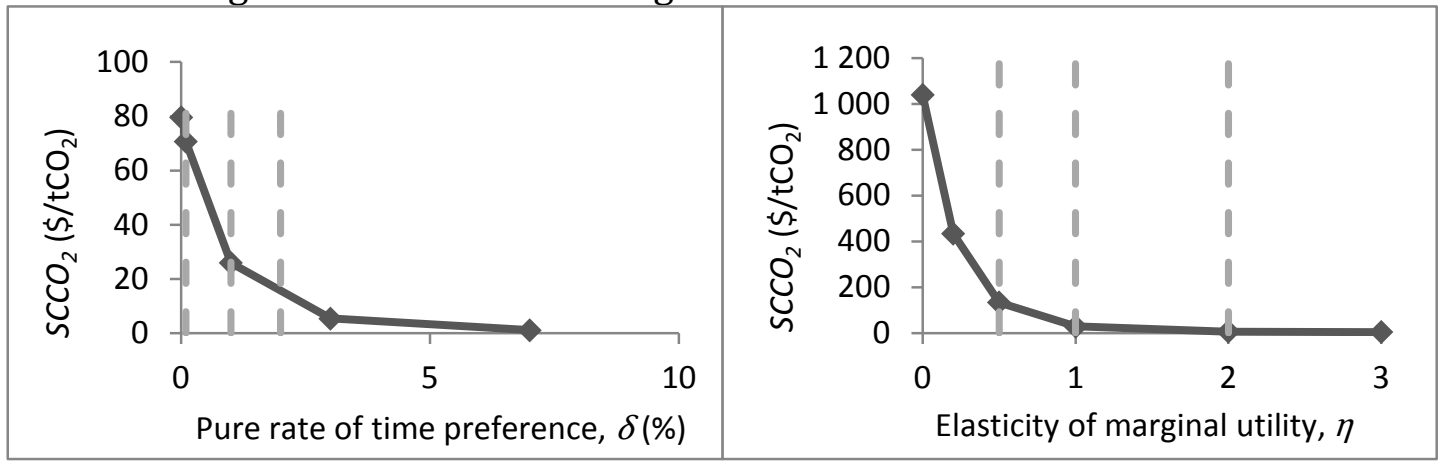

Figure 1: How the $\mathrm{SCCO}_{2}$ mean estimate varies depends on the discounting parameters PRTP and EMUC. The vertical lines refer to the min, mode, and max in the default triangular setting in PAGE2002. Simulations outside of this probability interval have also been run in order to show the full picture and to visualize the shape of the dependence of $\mathrm{SCCO}_{2}$ on these two parameters. This was done because discounting is controversial and no consensus has been reached on how it should be applied.

Notice the difference in scale of the vertical axis between the two diagrams, where there is a much higher maximum scale in the diagram for $\eta$ than for $\delta$. This means that $\mathrm{SCCO}_{2}$ is much more sensitive to $\eta$ than to $\delta$ in the lower end of the positive range. However, from a review of EMUC estimates in Evans (2006), values of $\eta<0$ seem unlikely from an empirical point of view.

Table 2 shows the influence of the calculation period in combination with three different discount schemes.

\begin{tabular}{lccccc}
\hline Time horizon & $\begin{array}{c}\text { PRTP } \\
\boldsymbol{\delta}(\boldsymbol{\%})\end{array}$ & $\begin{array}{c}\text { EMUC } \\
\boldsymbol{\eta}\end{array}$ & $\begin{array}{c}\text { Base case } \\
\left(\mathbf{\$} / \mathbf{t C O}_{2}\right)\end{array}$ & $\begin{array}{c}\text { Prolonged } \\
\left(\mathbf{\$} / \mathbf{t C O}_{2}\right)\end{array}$ & Ratio \\
\hline Base case & $(0.1 ; 1 ; 2)^{*}$ & $(0.5 ; 1 ; 2)^{*}$ & 28 & 29 & 1.04 \\
Stern & 0.1 & 1 & 74 & 76 & 1.03 \\
Low discount & 0.05 & 0.5 & 454 & 588 & 1.30 \\
\hline
\end{tabular}

Table 2: $\mathrm{SCCO}_{2}\left(\$ / \mathrm{tCO}_{2}\right)$ by calculation period. The different rows represent different discount schemes. The two first columns show the how the input parameters vary between the different discount schemes, and the last three columns are the results of the cost estimations. The columns named Base case and Prolonged represent the resulting $\mathrm{SCCO}_{2}$ with the default time horizon (the year 2200) and with a prolonged time horizon (the year 3000), respectively. Ratio is the unitless ratio of the Prolonged value to the Base case value. *Denotes a triangular probability density function with (min; mode; max). 
In Table 3 the social cost of three different GHGs are displayed, along with global damage potentials, for the year 2001.

\begin{tabular}{|l|c|cc|cc|}
\hline GHG & \multirow{2}{*}{$\begin{array}{c}\text { Lifetime* } \\
\text { (Years) }\end{array}$} & \multicolumn{2}{|c|}{ Social cost $\mathbf{( \$ / t o n ) ~}$} & \multicolumn{2}{c|}{ Global damage potential } \\
\cline { 3 - 6 } & & Base & Stern & Base & Stern \\
\hline $\mathbf{C O}_{2}$ & & 22 & 60 & & \\
$\mathbf{C H}_{\mathbf{4}}$ & 12 & 337 & 794 & 15 & 13 \\
$\mathbf{S F}_{\mathbf{6}}$ & 3,200 & 892,772 & $2,740,344$ & 40,961 & 45,335 \\
\hline
\end{tabular}

Table 3: Social cost and global damage potentials in 2001 for three different GHGs using Base case and Stern discounting. *Atmospheric lifetimes are from IPCC TAR (2001).

Figure 2 shows the growth rate of the social costs of the three GHGs using Base case and Stern discount schemes.

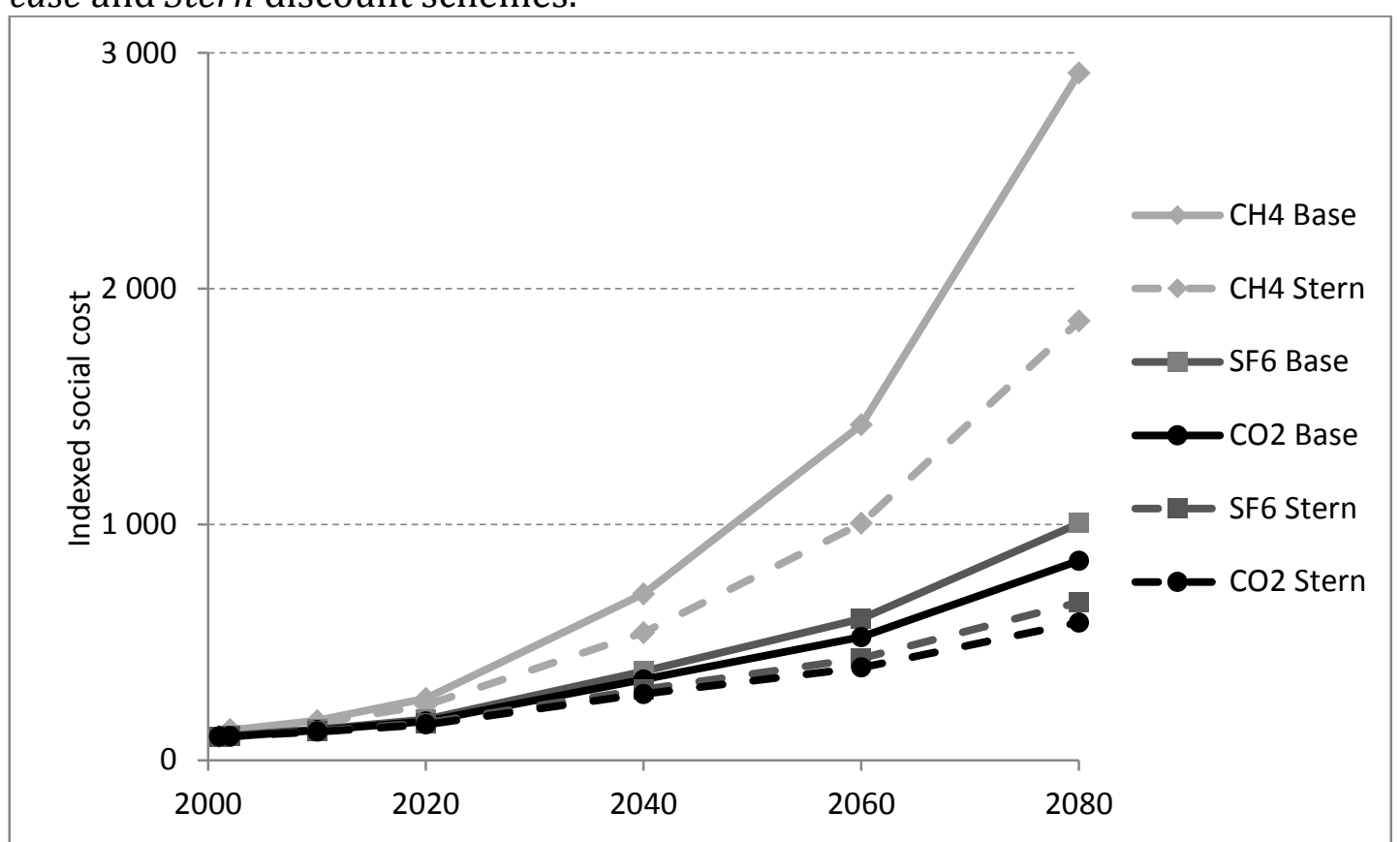

Figure 2: Indexed present value of the mean estimates of the social costs of three different climate gases for various emission years using Base case and Stern discounting.

\section{DISCUSSION}

The partial sensitivity analysis shows that the variations of $\mathrm{SCCO}_{2}$ with respect to both PRTP and EMUC are approximately negatively exponential in shape. The negative relationships are consistent with previous literature, such as Hope (2008a), and the reason for this is that with a high discount rate future damages are more heavily discounted.

Table 2 shows that for both the Base case discount scheme and the Stern discount scheme the $\mathrm{SCCO}_{2}$ only increases by a few percent when the calculation period is significantly increased, meaning that the calculation period is not a big issue when it comes to analyses performed with these discount rates. However, when discounting is significantly reduced, as in the Low discount scheme, the increase in the calculation period results in a $30 \%$ greater increase of $\mathrm{SCCO}_{2}$. In this case, the calculation period is obviously an important issue. So how should we set the 
calculation period? In CBAs for investment projects (for example, in infrastructure) it is natural to base the answer to that question on the technical lifetime of the facility, perhaps in combination with considerations of how long the same facility is expected to be up to date with technical progress.

When it comes to climate change, there is no such natural limit. Instead, I argue that the time horizon should be based on the discount rate so that no significant truncation is made. Objections can be made that this could lead to time horizons that are too long, but it is better to have a smooth, continuous function because it makes no sense that one year will have a considerable value and the next year no value at all. The PAGE model is constructed so that the time horizon is chosen by the user as long as no more than 10 analysis periods are calculated in total. Thus it is possible for the idea presented here to be implemented without rewriting the model.

In line with the results in Waldhoff et al. (2014), Table 3 shows that with no $\mathrm{CO}_{2}$ fertilization, the global damage potential increases with discounting for the shortlifetime $\mathrm{GHG}\left(\mathrm{CH}_{4}\right)$, while for the long-lifetime $\mathrm{GHG}\left(\mathrm{SF}_{6}\right)$ the global damage potential decreases with discounting. Waldhoff et al. performed analyses for three different PRTP values; $0.1 \%$, which is the same as in the Stern discount scheme in the present study; $1 \%$ which is the mode of the of the Base case discount scheme in the present study; and for 3\%. The magnitudes of the results are comparable between the studies but differs somewhat. For $\mathrm{CH}_{4}$, both the estimates for the Base case and the Stern discount scheme are most similar to the estimates for the $0.1 \%$ PRTP in Waldhoff et al. (2014). For SF 6 on the other both the estimates for the Base case and the Stern discount scheme are most similar to the estimates for the 1\% PRTP Waldhoff et al. (2014). This means that estimates of the global damage potentials in PAGE2002 are both somewhat smaller and less sensitive to the PRTP than in the FUND model, and it is not obvious why.

The results shown in Figure 3 imply that the higher the discount rate, the higher the growth rate of the social cost of GHGs. This type of analysis has to my knowledge not previously been performed, but additional calculations on the results in Table A1 in Marten \& Newbold (2012) confirm the result presented here. Thus one of the main drivers behind the increase of $\mathrm{SCCO}_{2}$ is discounting. Because total gross domestic product is projected to be higher in the future, damages will also be higher. The further into the future a unit of GHG is emitted, the less this increase is discounted. Another reason for the growth of $\mathrm{SCCO}_{2}$ is that concentrations are higher in the future and thus the marginal cost is growing (at least partly) with higher concentrations, although this effect might be less important in the model presented here. If $\mathrm{CO}_{2}$ is emitted in the year 2000, a fraction of that emission will have disappeared from the atmosphere by 2080 . However, because the default stop year for the PAGE2002 model is 2200, it might underestimate the increase in $\mathrm{SCCO}_{2}$.

From Figure 3 one can see that the social cost of methane grows much faster 7 than the corresponding cost of carbon dioxide, which is consistent with the

\footnotetext{
${ }^{7}$ At a mean rate of $4.2 \%$ for the Base case
} 
results in Marten \& Newbold (2012). Because of its short atmospheric lifetime, the damage incurred by methane depends on current conditions when emitted. This means that the slope of the methane cost curve reflects an increase in damage costs over time due to higher temperature rises and economic growth. Therefore, the social cost of methane cannot be estimated by a linear amplification of the $\mathrm{SCCO}_{2}$ by using, for example, the GWP (IPCC 20018), but should ultimately be modeled explicitly. Also, because the GWP of methane varies greatly with the length of time considered (due to its very short atmospheric lifetime), it is unwise to use this measure. The results of the present study show that the global damage potential of $\mathrm{CH}_{4}$ varies between 13 (Stern at year 2001) and 53 (Base case at year 2080). It is higher in all years for the low discount scheme compared to the high discount scheme, and it increases over time for both discount schemes.

Surprisingly, the shapes of the curves in Figure 2 for $\mathrm{SF}_{6}$ are very similar to the ones for $\mathrm{CO}_{2}$, with even slightly larger increases. Because of the long atmospheric lifetime of $\mathrm{SF}_{6}$, one would expect global damage potentials to evolve in the opposite direction compared to $\mathrm{CH}_{4}$. The implication of these results, if they are repeatable, is that the social cost of $\mathrm{SF}_{6}$ might be approximated to be proportional to that of $\mathrm{SCCO}_{2}$. The results of the present study show that the global damage potential of $\mathrm{SF}_{6}$ varies between 41,000 (Base case in year 2001) and 52,000 (Stern in year 2080). These results are significantly higher than the values of GWP in the IPCC TAR (IPCC 2001) and the IPCC Fourth Assessment Report (IPCC 2007) reports ${ }^{9}$, but the results of the present study are within the range of global damage potentials with no $\mathrm{CO}_{2}$ fertilization presented in Waldhoff et al (2014). This supports the conclusion that global damage potentials should be calculated by an IAM rather than by using the GWP. $\mathrm{CO}_{2}$ fertilization should be included in such a valuation, thus the estimates from, for example, Figure 9 in Waldhoff et al. (2014) for an appropriate PRTP could be used in policy evaluation. However, for the estimates that include $\mathrm{CO}_{2}$ fertilization in that diagram, unexpected results again show up and the global damage potential increases for both a reduction and an increase of PRTP compared to the base case of $1 \%$.

\footnotetext{
${ }^{8}$ Ch. 6.12 Global Warming Potentials

${ }^{9}$ In those two reports, the GWP of SF6 varies depending on the time horizon between 15,100 (for a 20 year time horizon in TAR) and 32,600 (for 500 years in AR4).
} 


\section{CONCLUSIONS}

The main conclusions are that the calculation period should ultimately be modeled to be consistent with the discount rate and that global warming potentials cannot be used to calculate the social cost of other climate gases. The latter might be especially important when it comes to short-lived GHGs.

Most models have a fixed time horizon that is chosen to be appropriate for the default discount rate of each model. The results of the present study show that if the discount rate is radically altered, the results may by heavily truncated by the default choice of time horizon. As a solution, I propose that the time horizon ultimately should be modeled as a function of the discount rate. If the proposed method leads to calculation periods that are perceived to be unreasonably long, the discount rate should be reconsidered.

The analysis of global damage potentials presented here has largely confirmed the results and conclusions of previous studies on this issue, notably those of Marten and Newbold (2012) and Waldhoff et al. (2014). I have further shown that discounting is an important driver of increases in the social cost of GHGs. In addition I have noted that the global damage potentials of sulfur hexafluoride sometimes behave in the opposite direction from what is expected when temporal parameters are varied. This phenomenon occurred both in the present study and in Waldhoff et al. (2014), and thus warrants further investigation in the future. 


\section{REFERENCES}

Anthoff, D., Tol, R. S. J. \& Yohe, G. W. (2009), "Risk aversion, time preference, and the social cost of carbon", Environmental Research Letters, vol. 4

Baum, S. (2009), "Description, prescription and the choice of discount rates", Ecological Economics, vol. 69, pp. 197-205

Dasgupta, P. (2008), “Discounting Climate Change”, Journal of Risk and Uncertainty, vol. 37, pp. 141-169.

Dietz, S., Anderson, D., Stern, N., Taylor, C. \& Zenghelis, D. (2007), "Right for the Right Reasons: A final rejoinder on the Stern Review", World Economics, vol. 8 , no. 2

Eyre, N., Downing, T., Hoekstra, R. \& Rennings, K. , 1999. Global warming damages. Final Report of the ExternE Global Warming Sub-task. DGXII, EC, Brussels. Available at http://www.externe.info/

Evans, D., (2006), "The elevated status of the elasticity of marginal utility of consumption", Applied Economics Letters, 2004, 11, pp. 443447. http://dx.doi.org/10.1080/1350485042000189541

Gollier, C. (2009), Expected net present value, expected net future value, and the Ramsey rule, Working paper 2009-06-13

Guo et al (2006), Discounting and the Social Cost of Carbon: a closer look at uncertainty, Environmental Science \& Policy, vol. 9, pp. 205- 216.

Hope C, (2005), "The climate change benefits of reducing methane emissions", Climatic Change, Vol. 68, pp. 21-39.

Hope, C. (2006), “The Marginal Impact of $\mathrm{CO}_{2}$ from PAGE2002: An Integrated Assessment Model Incorporating the IPCC's Five Reasons for Concern", The Integrated Assessment Journal, vol. 6, iss. 1, pp. 19-56

Hope, C. (2008a), "Discount rates, equity weights and the social cost of carbon", Energy Economics, vol. 30, pp. 1011-1019

Hope (2008b), C. "Optimal carbon emissions and the social cost of carbon over time under uncertainty", The Integrated Assessment Journal, vol. 8, no. 1, pp. $107-122$

Intergovernmental Panel on Climate Change, IPCC (2000), Emissions Scenarios, CAMBRIDGE UNIVERSITY PRESS, The Edinburgh Building, Cambridge CB2 2RU, UK. Available at: http://www.ipcc.ch/ipccreports/sres/emission/index.php?idp=0

Intergovernmental Panel on Climate Change, IPCC (2001), IPCC Third Assessment Report: Climate Change 2001 (TAR): The Scientific Basis, 
CAMBRIDGE UNIVERSITY PRESS, The Edinburgh Building, Cambridge CB2 2RU, UK. Available

at: http://www.csun.edu/ hmc60533/CSUN 630E S2004/climate\%20 change/climate change 2001 tech summary.pdf

Intergovernmental Panel on Climate Change, IPCC (2007) IPCC Fourth Assessment Report: Climate Change 2007 (AR4),Working Group I Report "The Physical Science Basis", ch. 2.10.2, CAMBRIDGE UNIVERSITY PRESS, The Edinburgh Building, Cambridge CB2 2RU, UK. Available at: http://www.ipcc.ch/publications and data/ar4/wg1/en/ch2s2-10$\underline{\text { 2.html }}$

Marten, A. L., Newbold, S. C., (2012), "Estimating thesocialcostofnon-CO2 GHG emissions: Methane and nitrous oxide", Energy Policy, vol. 51, pp. 957972. Available at: http://www.sciencedirect.com/science/article/pii/S03014215120085 $\underline{55}$

Stern, N. (2006). The Economics of Climate Change: The Stern Review. Cambridge, UK, Cambridge University Press. Available at: http://www.hm-treasury.gov.uk/stern review report.htm

Waldhoff, S., Anthoff, D., Rose, S. and Tol, R.S. J., (2015), “The Marginal Damage Costs of Different Greenhouse Gases: An Application of FUND", Economics: The Open-Access, Open-Assessment E-Journal, vol. 8, Available at: http://dx.doi.org/10.5018/economics-ejournal.ja.2014-31

Weitzman, M. L, (2009), "On modeling and interpreting the economics of catastrophic climate change", The Review of Economics and Statistics, vol. XCI, no. 1 